\title{
A PRÁTICA DE ENFERMAGEM NO SISTEMA PENAL: LIMITES E POSSIBILIDADES
}

The nursing practice inside the penal system: limits and possibilities

La práctica de enfermería en el sistema penal: límites y posibilidades

Mônica Oliveira da Silva e Souza ${ }^{1}$

Joanir Pereita Passos²

\section{RESUMO}

0 presente trabalho teve como objetivos identificar os princípios que norteiam a prática de enfermagem e discutir os limites e as possibilidades da atuação da equipe de enfermagem nos serviços de saúde do Sistema Penal do Estado do Rio de Janeiro. Para alcançar os objetivos propostos, realizou-se um estudo descritivo com abordagem qualitativa. 0 cenário foi um hospital geral penitenciário, e foram entrevistados 30 profissionais de enfermagem. A coleta de dados se deu mediante a técnica de entrevista. Os resultados evidenciaram que a prática do cuidado e a relação de ajuda são os princípios que norteiam a atuação da enfermagem na Unidade Hospitalar Penitenciária, suas possibilidades são semelhantes às da realidade extramuros, e a presença do agente penitenciário e a periculosidade são os elementos limitantes da prática de enfermagem.

Palavras-chave: Saúde. Enfermagem. Prisões.

\begin{abstract}
The aims of this paper were to identify the principles that guide the nursing practice and to discuss limits and possibilities faced by a nursing team while working at the health services offered in the Rio de Janeiro State Penitentiary System. In order to reach the suggested goals, it has been written a descriptive study with qualitative approach. The scenario was a Penitentiary General Hospital and there were interviewed 30 professionals nursing interviewed. The data was collected through a technique of interview. The results showed that care practice and assistance relationship are the principles which guide the nurse's performance at a Penitentiary Hospital Unit. It has been also showed that the possibilities are the same as the ones we see beyond walls, and that the presence of a penitentiary agent, as well as the dangerous, are limitations for the nursing practice.
\end{abstract}

\section{Resumen}

El presente trabajo tuvo como objetivos identificar los principios que nortean la práctica de Enfermería y discutir los límites y las posibilidades de la actuación del equipo de Enfermería en los servicios de salud del Sistema Penal del Estado de Río de Janeiro. Para llegar a los objetivos propuestos, se realizó un estudio descriptivo con abordaje cualitativo. Tuvo como escena un Hospital General Penitenciario y habían sido entrevistados 30 profesionales de enfermería. La recolecta de los datos ocurrió por medio de la técnica de entrevista. Los resultados evidenciaron que la práctica del cuidado y la relación de ayuda son los principios que nortean la actuación de la enfermería en la Unidad Hospitalar Penitenciaria, sus posibilidades son semejantes a las de la realidad fuera de los muros y la presencia del agente penitenciario y la peligrosidad es el elemento que limita la práctica de enfermería. 


\section{INTRODUÇÃO}

As ações inerentes à profissão de Enfermagem quer sejam administrativas ou assistenciais, dadas as especificidades do Sistema Penal, se diferenciam na sua aplicabilidade da realidade extramuros. Para 0 atendimento das necessidades de saúde da população carcerária, o sistema prisional dispõe de profissionais de saúde nas unidades hospitalares prisionais.

Dada a importância da atenção de saúde deste grupo específico, os Ministérios da Justiça e da Saúde instituíram o Plano Nacional de Saúde no Sistema Penitenciário através da Portaria Interministerial $n^{0} 1.777$, de 09 de setembro de 2003 que prevê a inclusão da população penitenciária no Sistema Único de Saúde (SUS), garantindo que o direito à cidadania se efetive na perspectiva dos direitos humanos ${ }^{1}$.

Deste modo, a cidadania é um atributo de qualquer membro do Estado ou país e portador de direitos e deveres. 0 cidadão tem faculdade de gozar e exercer plenamente direitos civis e políticos. No Estado moderno, cidadão é sinônimo de homem livre, na cidade e no campo, portador de direitos e obrigações a título individual, assegurados em lei. Os direitos da cidadania podem ser civis, políticos e sociais ?

Segundo o art. 38 do Código Penal,"o preso conserva os direitos não atingidos pela perda de liberdade,impondo-se a todas as autoridades o respeito à sua integridade física e moral"3.

Assim, o acesso dessa população a ações e serviços de saúde é legalmente garantido pela Constituição Federal de 1988; pela Lei $n^{0} 7.210$, de 11 de julho de 1984, que institui a Lei de Execução Penal; pela Lei no 8.080 de 1990, que regulamenta o SUS e pela Lei $n^{0} 8.142$ de 1990, que dispõe sobre a participação da comunidade na gestão do SUS $S^{4 ; 5 ; 6 ; 7}$.

Isto nos leva a refletir que os apenados, independentemente da natureza de sua transgressão, mantêm o direito de gozar dos mais elevados padrões de assistência de enfermagem, pois se encontram privados de liberdade e preservando os demais direitos humanos inerentes à sua cidadania.

Neste contexto, pensamos que a enfermagem pode contribuir para o resgate da condição de vida digna das pessoas, tanto do ponto de vista biológico, quanto social e psicológico, proporcionando confor to e bem-estar, minimizando iniciativas que estimulem a discriminação ou preconceito; e ainda respeitando os princípios éticos e legais, com vistas a resgatar o sentido da existência humana.

Em face dessa clientela específica e com necessidades diferenciadas, dada a vivência profissional, percebemos que é necessário que a Enfermagem no Sistema Penal desenvolva as suas atividades centradas na necessidade do indivíduo, considerando os aspectos éticos e legais da profissão e ainda levando em consideração as características próprias do Sistema Penal.

As unidades penitenciárias talvez sejam a parte obscura que nos recusamos a ver, o outro lado da moeda. É como se estivéssemos falando de um mundo à parte. Às vezes, pelo menos esta é a sensação que temos, de estranheza a este mundo tenebroso e frio, que causa arrepios muitas vezes só de falar, pelos crimes praticados, pela falta de liberdade, pela agressividade, pelos conflitos e pela insegurança permanente no desempenho das atividades.

De acordo com a Lei de Execuções Penais (LEP) - Lei $n^{0}$ 7.210 de 1984, que regulamenta o cumprimento das penas restritivas de liberdade e inclui orientações detalhadas, os presos deverão ser classificados e separados por sexo, antecedentes criminais e status legal (condenados ou aguardando julgamento). A mesma lei assegura alimentação, vestuário, instalações higiênicas, atendimento médico, assistência jurídica, assistência educacional e preservação dos direitos não atingidos pela perda de liberdade 5 .

Na prática, contudo, poucas destas regras são respeitadas. As mulheres presidiárias são separadas dos homens, os menores são, grande parte, mantidos fora das prisões de adultos, e expoliciais são mantidos em celas separadas dos outros presos; assim, na maior parte das instituições penais, pouco mais é realizado no sentido de separar as diferentes categorias de presos por crimes cometidos.

As unidades prisionais do Rio de Janeiro não se diferenciam muito das unidades espalhadas pelo país, os presos são normalmente forçados a permanecer em terríveis condições de vida nos presídios, penitenciárias e delegacias.

0 Departamento do Sistema Penitenciário do Rio de Janeiro (DESIPE) é um órgão da Secretaria de Administração Penitenciária, de caráter descentralizado e relativamente autônomo, responsável por coordenar e implementar as ações que dizem respeito às penas privativas de liberdade. Dentre as unidades administrativas inserem-se as Unidades Penais e Hospitalares.

Nas unidades hospitalares são os hospitais-presídio que se destinam ao tratamento de saúde dos presos. Em cada unidade prisional, o DESIPE apresenta um ambulatório que atende os casos menos graves, encaminhando os demais para o Hospital Central, que é a referência no atendimento médico a todas as Unidades Prisionais, aos demais Hospitais do Departamento do Sistema Penitenciário, às Casas de Custódias do DESIPE, ao Departamento de Ações Sócio-Educativas (DEGASE), à Polinter, a Polícia Federal e a todas as Delegacias. 0 Hospital Central atende em regime de plantão de 24 horas e em Ambulatórios de especialidades médicas.

0 apenado, quando hospitalizado na unidade prisional, encontra-se diante de uma situação peculiar, está sob a custódia do Estado, sendo duplamente acompanhado pela equipe de saúde da unidade hospitalar e a equipe de segurança presente na unidade.

Em "Manicômios, prisões e conventos", Goffman 8 inclui as prisões como exemplo de um tipo de estabelecimento: a instituição total, dividindo-a em cinco grupos, dos quais destacamos aquele organizado para proteger a comunidade contra os perigos intencionais, como as cadeias, e os campos de concentração. Nestes locais, o bem-estar das pessoas ali isoladas não representa uma preocupação.

Assim, descreve que as instituições criam barreiras entre 0 internado e o seu mundo exterior, sendo esta a primeira "mutilação do EU". Esta mutilação se dá através de tensões 
entre a vida na instituição e a vida anterior do internado, adquirindo importante significado no próprio processo de admissão, em que o mesmo recebe roupas padronizadas, tem cabelos cortados e um número de identificação, além de ser pesado, fotografado e ter colhidas suas impressões digitais. Além disso, a "ausência de bens é mais uma das formas de mutilação do eu" 8:23.

É importante destacar que o apenado, embora vislumbre e imagine constantemente a sua vida fora da instituição, sentese extremamente inseguro quando este momento se aproxima, e alguns criam diversos problemas para lá permanecer. Nesse sentido é comum a enfermagem receber a notícia de alta do paciente e, ao informar ao apenado tal fato, o mesmo se recusar a deixar o hospital, pois diz estar se sentindo mal e que não há condições de ser transferido para a sua unidade.

Existe, porém, neste caso, a peculiaridade de que, ao receber alta, o apenado não vai para casa, mas retorna para sua cadeia de origem. Assim, embora a prática de enfermagem e os cuidados gerais sejam semelhantes aos de uma unidade hospitalar extramuros, o fato de que o ambiente extra-hospitalar não seja a casa e a rua, mas uma prisão, impõe aos profissionais da assistência de saúde diversas mudanças de conduta, permitindo, muitas vezes, que o período de internação deste paciente seja maior que a realidade extramuros.

Este indicador, que seria ruim para uma unidade hospitalar comum, aqui pode significar um cuidado maior com o paciente, que, voltando à prisão de origem, poderá se deparar com as situações de estresse e más condições de higiene, incompatíveis para a sua recuperação.

Esses são aspectos que nos inquietam e que motivaram a realização desse estudo. Assim, para compreender a situação no que se refere a limites e possibilidades da atuação da Enfermagem, realizou-se um estudo com os objetivos de identificar os princípios que norteiam a prática de enfermagem e discutir os limites e as possibilidades da atuação da equipe de enfermagem nos serviços de saúde do Sistema Penal do Estado do Rio de Janeiro.

\section{METODOLOGIA}

Optamos em realizar um estudo descritivo que teve como propósito observar, descrever e explorar aspectos relativos à atuação de enfermagem em unidades hospitalares penitenciárias.

Os estudos descritivos são aqueles que têm como objetivo primordial a descrição das características de determinada população, levantando as suas opiniões, atitudes e crenças através da identificação de relações entre variáveis, com a possibilidade de determinar a natureza destas relações ${ }^{9}$.

Trata-se de uma pesquisa de abordagem qualitativa, na qual o envolvimento do pesquisador pode resultar ainda em alguns resultados idiossincráticos devidos à natureza subjetiva da investigação ${ }^{10}$.

Esta pesquisa teve seu projeto avaliado e aprovado pelo Parecer $N^{\circ}$ 008/2006 do Comitê de Ética em Pesquisa da Universidade Federal do Estado do Rio de Janeiro (UNIRIO).
Todos os procedimentos metodológicos obedeceram aos padrões estabelecidos pela Resolução 196/ 96, que trata das Normas de Pesquisa Envolvendo Seres Humanos ${ }^{11}$. Foi realizada no Hospital Central do Sistema Penitenciário do Estado do Rio de Janeiro. Os sujeitos desta pesquisa constituíram-se de 30 profissionais pertencentes à equipe de enfermagem, do quadro efetivo, independente do tempo de exercício profissional e institucional, lotados no hospital do cenário de estudo.

Para a coleta de dados, utilizamos como instrumento a entrevista individual em local reservado. As entrevistas foram realizadas em horários pré-agendados com os sujeitos da pesquisa. Para garantir o anonimato dos participantes foram todos identificados pela letra "E" e o respectivo número à ordem de sua entrevista.

Para nortear a entrevista, elaboramos um roteiro com algumas proposições ou questões orientadoras da investigação. E, na análise das entrevistas, adotamos a técnica de análise de conteúdo, especificamente a análise temática, usamos os seguintes procedimentos: leitura e releitura das entrevistas, mapeamento dos discursos individuais destacando-se as palavras e frases; análise do discurso mediante síntese das entrevistas, baseada nas palavras e/ou frases interpretadas pelo pesquisador.

\section{APRESENTAÇÃO E DISCUSSÃO DOS DADOS}

0 estudo foi realizado com a participação de 30 sujeitos: 3 enfermeiros, 16 técnicos de enfermagem e 11 auxiliares de enfermagem. A escolha de trabalhar com as diversas categorias de enfermagem se deve ao fato de possibilitar uma visão mais ampla destes grupos, que apesar de terem atribuições específicas, possuem um mesmo código de ética com os mesmos princípios fundamentais da profissão.

Com relação ao tempo de exercício profissional relativo ao desempenho das atividades de enfermagem no Sistema Penal, variou entre 4 e 18 anos. Cabe ressaltar que a maioria dos entrevistados ingressou no Sistema Penal a partir de 1998, quando houve o $1^{\circ}$ Concurso Público para a área de saúde do DESIPE da Secretaria de Administração Penitenciária.

Do contingente da equipe de enfermagem entrevistado, 26 são do sexo feminino e 4 são do sexo masculino. Esses dados são condizentes com o que se refere Figueiredo ${ }^{12}$ ao considerar que a enfermagem é composta, em sua maioria, por profissionais do sexo feminino.

Nas entrevistas foi possível notar que a escolha de atuar nos serviços de saúde do Sistema Penitenciário do Estado do Rio de Janeiro se deu por uma questão de estabilidade do concurso público (13 profissionais) e por oferecerem um bom salário na época de seu ingresso (16 profissionais); apenas um possuía experiência anterior no Sistema Penal.

No que diz respeito à importância atribuída ao desempenho de suas atividades de Enfermagem no Sistema Penal Hospitalar, apontam para dois elementos significativos: a prática do cuidado e a relação de ajuda.

Na Prática do Cuidado, o cuidado é apontado pelos entrevistados como um fator de responsabilidade da 
enfermagem e como a compreensão do apenado em sua particularidade, sem discriminação, como se pode observar nas seguintes falas:

A enfermagem contribui. Acredito que eu consiga exercitar os meus conhecimentos. Procuro ver a prática do cuidado. Trabalho como uma instituição pública. (E 1)

Cuidar do paciente como um todo. Cuidar como um paciente comum. Não é parte criminal dele, e sim um paciente. (E 5)

Prestar cuidado, pois ninguém liga para essa gente. (E 7)

Assistência ao paciente sem preconceitos. (E 8)

Uma forma de prestar atendimento ao paciente que está excluso da sociedade. (E 10)

Os presos precisam dos cuidados de enfermagem. A enfermagem não os vê como presos. (E 16)

Eu acho que na assistência devemos tentar, dentro das possibilidades, dar a mínima condição de saúde. (E 20)

Eu gosto de cuidar de doentes, tanto faz se presos ou não. (E 28)

Isso corrobora Valdow ${ }^{13}$, que diz que o cuidado como atitude ética deve ser entendido como uma forma de viver em que haja compromisso, uma responsabilidade em estar no mundo.

Reafirmando a posição da equipe de enfermagem, Potter e Perry ${ }^{14}$ relatam que o cuidado serve como valor central da profissão, proporcionando um referencial organizador para a pesquisa, educação e desenvolvimento de teorias profissionais; apontam o cuidado como uma peculiaridade humana e que este aspecto universal do cuidado ajuda a enfermagem a reconhecer que cada cultura desenvolve atitudes e expectativas específicas sobre o cuidado e que devem ser incorporadas dentro da prática profissional. Ainda, o cuidado para enfermagem é oferecer ao outro o resultado de nossos talentos, preparos e escolhas, ultrapassando a dimensão unicamente racional e assistencialista do fazer para alcançar a dimensão relacional e multidimensional do cuidado ${ }^{15}$.

Sendo assim, pensamos que a enfermagem, ao cuidar do outro, estabelece uma relação na qual devem ser considerados os valores, ideais, preconceitos, crenças, expectativas, experiências anteriores, que estão presentes em cada um dos sujeitos envolvidos e que influenciam a relação. Deste modo, o cuidado se caracteriza por um processo diversificado, que assume diferentes contextos conforme o momento e o vivido na relação que se estabelece entre sujeito (apenado) e profissional (enfermagem).

Desta forma, acreditamos que o ambiente onde ocorrem as relações para o cuidado também deve ser considerado, pois a forma como o sujeito apreende o ambiente como o contexto humano de relações e se percebe no mesmo pode influenciar tanto favorecendo quanto dificultando a integração e 0 crescimento dos sujeitos envolvidos na relação.

Essas relações tão importantes para a prática do cuidado sofrem interferência direta do ambiente, tão necessário para recuperação do cliente. 0 ambiente aqui é mencionado como 0 local com o qual fazemos nossas trocas, e com os outros da equipe de saúde e com nós mesmos. Diante desta relação, ambiente de trabalho (condições) e prática do cuidado na assistência de enfermagem, destacam-se alguns depoimentos:

Minimizar os efeitos da reclusão através da assistência. (E 18)

Procuro trabalhar diretamente com o preso, prestação de cuidados. Parto do princípio do respeito, não dou abertura para brincadeira, trato dignamente. Nunca os chamo pelos apelidos. ( $E$ 24)

O trato muda um pouco. Mantenho certa distância. Percebo que é uma distância para autopreservação e manter o objetivo profissional. Entrar na enfermaria, fazer a medicação, não tenho afeto. ( $E$ 27)

Portanto, é com este entendimento que a equipe de enfermagem ao cuidar dos apenados estabelece uma relação permeada tanto de valores morais quanto éticos e sociais. Destaca-se, ainda a relação de ajuda, que não acontece imediatamente como um elemento importante no desempenho das atividades de enfermagem no Sistema Penal, o que torna necessária a construção desta relação de ajuda mediante a prática do cuidado, utilizando-se a comunicação verbal como ferramenta para o desempenho das suas atividades.

Tudo de bom, a enfermagem faz milagres na cadeia. (E 12)

Serve para mostrar que, eles querendo, existe sempre alguém para ajudar. (E 14)

Importante para aliviar a tensão emocional do preso. Não vejo como preso, e sim como doente. A relação agente/preso é bem diferente. 0 guarda para o preso é uma ameaça, a enfermagem é um refrigério. (E 19)

Os pacientes são carentes. Às vezes basta uma palavra de conforto, para mudar o comportamento. (E 21)

Ajudar aqueles que estão oprimidos. Hoje, um apoio mais psicológico do que para a saúde quer dizer saúde mental. (E 22)

Total, porque a enfermagem re-humaniza o preso. Pela prática de enfermagem, tratando como trata lá fora, com as mesmas preocupações. (E 26)

$\mathrm{Na}$ fala dos entrevistados percebemos que na realidade hospitalar do Sistema Penal, a Enfermagem é a parte da equipe multidisciplinar que mais se aproxima do cliente. Destacamos 
na fala dos entrevistados que a equipe de enfermagem serve como elo para os demais profissionais de saúde da instituição.

0 contato direto é com a enfermagem. E $80 \%$ ficam com os auxiliares e técnicos. Toda a informação chega através da equipe de enfermagem. (E 15)

A Enfermagem pode utilizar-se das interações mesmo considerando o contexto hostil das unidades penais, agindo, portanto, também como um facilitador na medida em que promove a abertura de uma rede de comunicações, incentivando a pessoa a tomar a palavra, falando sobre assuntos relativos às suas necessidades, e permitindo que a pessoa faça suas próprias escolhas $^{16}$

Com esse entendimento, as ações de enfermagem podem configurar-se em uma interação terapêutica, pois segundo Furegato ${ }^{16}$ "ser terapêutico significa interagir de forma a ajudar o outro naquilo que ele precisa, no momento". Sendo assim, tal interação pode se transformar em uma relação efetiva de ajuda.

Benjamim ${ }^{17}$ define ajuda como: um ato de capacitação (da parte de quem busca ajuda) e um ato de doação (da parte de quem oferece ajuda). Desta forma, a intenção de ajuda deve estar centrada na pessoa, e não apenas no problema que ela apresenta.

Em relação à descrição do trabalho de enfermagem exercido no Sistema Penal, constatamos que as possibilidades do desempenho das ações de enfermagem convergem ao desenvolvimento de habilidades e competências de enfermagem, sendo as mesmas da realidade extramuros.

Cuidados gerais de enfermagem: aferição de $P A$, sinais vitais, administração de medicamentos, assistência psicológica. (E 1)

Curativos, banho de leito, ouvir muito o paciente, 0 tempo todo passando a psicólogo. (E 6)

Curativos, medicação e encaminhamento para outros profissionais. (E 8)

Medicação, cuidados com a higiene pessoal e curativos. (E 9)

Medicação, curativos. Ouço a maior parte do tempo, tem paciente que nem doente está, é mais emocional. (E 15)

Medicação, curativos, sinais vitais, conselhos $e$ conversas. (E 14)

Quanto aos limites da realidade intramuros da unidade hospitalar do Sistema Penal, na fala dos sujeitos percebemos que a falta de autonomia (relacionada à locomoção de ir e vir) para prestar a assistência emerge pela presença do agente penitenciário, pela periculosidade do paciente, o que é apontado como fato significativo que afeta diretamente as ações desenvolvidas pela equipe de enfermagem.

Cabe ressaltar que o agente penitenciário é um profissional que não faz parte do quadro efetivo da realidade extramuros, entretanto, no Sistema Penal, está presente a todo o momento, conforme constatado nos seguintes depoimentos:

Apesar de serem pacientes, não são comuns. Requerem cuidados, não devemos confiar totalmente, sempre alerta, são pessoas de alta periculosidade. (E 5)

O sistema me obriga a ser diferente. Dependo dos agentes, da periculosidade dos pacientes, mas os cuidados são os mesmos. (E 7)

Aqui existe uma insegurança constante com o detento porque a gente nunca sabe o que pode acontecer. (E 10)

Aqui se está diante de pessoas perigosas. (E 14)

Sim, risco de morte. Cheio de aparatos de segurança: grades e regras que dificultam o trato profissional enfermagem / paciente. (E 18)

Aqui você tem certeza que o paciente é preso. Pessoas com quem você tem que ter limitações. Lá a gente não conhece as pessoas. Aqui podemos receber uma faca no pescoço. (E 24)

Destaca-se que, apesar de a presença do agente penitenciário ser por vezes tida como vigilância constante por parte da enfermagem, esta mesma enfermagem clama por mais segurança dentro do Sistema Penal, pois se sente vulnerável devido à periculosidade do apenado e do Sistema em si.

Estes sujeitos do cuidado de enfermagem no Sistema Penal, ao adentrarem no Sistema Penal sofrem um processo de esvaziamento do seu EU em que tudo que foi apreendido deve ser esquecido ${ }^{8}$. Além de o apenado estar fora do ambiente que Ihe é familiar, o mesmo se apóia na enfermagem tornando-se um paciente mais solícito do que os outros da realidade extramuros, conforme podemos atestar nas falas abaixo:

Existe diferença. A parte psicológica do paciente é diferente. Cuidado é um todo. Precisa ouvir mais o paciente do que em uma instituição comum, devido à carência geral do paciente. (E 1)

Sim, os nossos pacientes são diferentes: são seres desligados da sociedade, aqui sabemos que eles são presos, temos que estar atentos o tempo todo com o paciente, tem que ter mais sensibilidade no trato com o paciente. (E 19)

Existe a carga psicológica, que é outra. Você não pode esquecer uma lâmina de bisturi, uma atadura, álcool, e nem podem ser dados. (E 23)

Toda a estrutura física oprime o profissional. Nós nos sentimos presos. (E 26)

Sendo assim, através das falas dos entrevistados, pude perceber que tanto a condição psicológica do sujeito do cuidado 
quanto dos profissionais de enfermagem que atuam no Sistema Penal é afetada pela situação de insegurança constante.

Quanto às dificuldades enfrentadas na realização das atividades de enfermagem nos serviços de saúde do Sistema penal, foram apontados pelos investigados: a falta de autonomia profissional, a precariezação dos serviços de saúde, a falta de infra-estrutura das unidades hospitalares e a dependência do agente penitenciário, as quais emergem nas respostas dos entrevistados:

A falta de espontaneidade por falta de abertura das celas pelo agente penitenciário, o que limita muitas vezes o trabalho de enfermagem, dando pressa à enfermagem, o tempo é remido e pequeno. (E.4)

Muitas: falta de material, falta de cooperação do paciente, o próprio ambiente não coopera, por exemplo, não posso ir muitas vezes ao mesmo paciente, o agente não gosta. A estrutura física é ruim, não há leitos e as comarcas são inadequadas. (E.7)

O espaço físico de cada cubículo é difícil, falta de material; é constrangedor estar no espaço tão apertado... falta de espaço, também acho às vezes que falta instrução para lidar com os presos. (E. 14)

Encontro muitas dificuldades básicas de material. As condições para desempenhar certos procedimentos: má iluminação. 0 desencontro de propósitos, a enfermagem versus agente penitenciário. O SOE (Serviço de Operações Externas) acha que queremos ser a mãe do paciente. Aqui é um hospital e uma prisão. Ele está sendo punido e cuidado ao mesmo tempo. A falta de padronização das rotinas. A burocracia. (E.27)

No estudo, a fala dos entrevistados revela que a autonomia (relacionada à locomoção de ir e vir) para realização da prática do cuidado que a enfermagem possui enquanto profissão, numa unidade hospitalar do Sistema Penal, fica condicionada ao serviço de segurança, pois a segurança está em primeiro lugar e, posteriormente, o tratamento dos apenados, conforme descrito nos depoimentos abaixo:

Existe na hora que você precisa fazer determinados cuidados, o agente não pode vir abrir. (E 5)

Encontro dificuldade: carência de material, preciso sempre ter um intermediário para desempenhar minhas funções. Incomoda muito a presença do agente. (E 6)

A falta de acesso imediato ao cliente que diz que está passando mal. O horário da enfermagem tem que ser igual ao do agente que acompanha você. (E 11)
Quanto às proposições sugestionadas pelos os entrevistados para facilitar as atividades de enfermagem no Sistema Penal, a segurança, a estrutura física/organizacional, a gestão de pessoas e os recursos materiais aparecem como áreas que, ao serem reestruturadas, facilitariam 0 desenvolvimento das atividades da equipe de enfermagem.

Apesar de a enfermagem estar cercada pela presença do agente penitenciário 24 horas, percebe-se que esta enfermagem clama por mais segurança, pois percebe que a segurança instalada no Sistema Penal é para que não haja fuga, e não para os profissionais de enfermagem.

A falta de um treinamento específico para a atuação no Sistema Penal é outro fator que traz insegurança para a equipe de enfermagem. A enfermagem não se sente preparada para atuar em rotas de fugas ou em rebeliões caso ocorra. Como podemos conferir nas falas abaixo:

A enfermagem precisa de mais segurança, pois não é o medo, mas o receio de acontecer qualquer coisa. (E 2)

Treinamento para a segurança da enfermagem para saber lidar com o paciente preso. (E 10)

A estrutura física do hospital é diferente das demais unidades hospitalares como, por exemplo: as camas são de alvenaria e nem todas as enfermarias possuem vaso sanitário, e sim um "boi" (louça enterrada no chão); este tipo de vaso sanitário é muito utilizado nas penitenciárias para que 0 apenado não quebre e não se machuque e nem cause dano a alguém com este material. A fala dos entrevistados revela a necessidade de uma reestrutura nas unidades hospitalares:

A estrutura física precisa ser mudada, por exemplo: reforma dos cubículos. (E 7)

A estrutura física das enfermarias é inadequada. Não há como levar a cadeira de rodas para os banheiros. (E 9)

Outro elemento apontado como proposição de melhoria para a equipe de enfermagem seria a construção de um Centro de Tratamento Intensivo dentro do Sistema Penitenciário do Estado do Rio de Janeiro, pois o apenado quando se encontra em estado grave precisa ser removido para um hospital da rede pública, e a enfermagem participará da transferência, o que causa muita aflição e insegurança na equipe, pois não é uma simples transferência, necessita de escolta policial, deixando a enfermagem mais uma vez vulnerável.

É necessária a construção de um hospital de grande porte. 0 hospital deveria estar preparado para o paciente nunca sair daqui, assim não precisaríamos nos expor para levar um paciente para a rede pública. (E 24) 
Outra sugestão referida pela equipe de enfermagem seria a construção de um Fórum dentro do Sistema Penal, pois os pacientes que não deambulam, mas que estão em perfeito juízo, ao serem convocados pelo Juiz, devem comparecer ao tribunal. Como o paciente está sob cautela do Estado em uma unidade hospitalar, a enfermagem acompanha este apenado até 0 tribunal, só retornando após o depoimento deste. É importante ressaltar que a enfermagem fica mais uma vez vulnerável diante desta situação.

Deveria haver uma estrutura em que o preso não precisasse sair do Sistema Penal, se tivesse um fórum eu não precisaria me expor. (E 24)

Com relação à gestão de pessoas, é apontada pelos entrevistados a necessidade de treinamento de segurança, de maior interação entre a equipe de enfermagem e 0 agente penitenciário e de um acompanhamento psicológico para os profissionais de enfermagem e agentes penitenciários.

\section{CONCLUSÕES}

0 estudo possibilitou aprofundar o conhecimento da realidade vivenciada pelos profissionais de enfermagem nos serviços de saúde do Sistema Penal, pois identificamos que a equipe de enfermagem que atua tem como princípios básicos a prática do cuidado e a relação de ajuda na atenção à saúde dos apenados, que sofrem interferências do próprio Sistema.

Esta interferência foi detectada nos depoimentos dos entrevistados, que, na realização da prática do cuidado de enfermagem, se deparam com algumas limitações, dado que se trata de uma unidade hospitalar prisional onde a segurança prevalece em relação ao tratamento de saúde dos apenados.

0 estudo ainda propiciou analisar as limitações e possibilidades de atuação da equipe de enfermagem em uma unidade hospitalar prisional. Dentre as limitações verificam-se a presença do agente penitenciário e a periculosidade, que dificultam a autonomia do profissional de enfermagem no desempenho de suas ações. Como possibilidades constatamos as mesmas habilidades e competências exercidas na realidade extramuros. Entretanto, apesar de a presença do agente penitenciário ser, por vezes, tida como vigilância constante por parte da enfermagem, esta mesma enfermagem clama por mais segurança dentro do Sistema Penal, pois se sente vulnerável devido à periculosidade do apenado e do Sistema em si.

Porém, apesar dos limites impostos pelo Sistema Penal, a enfermagem, que desempenha suas atividades neste Sistema, em uma unidade nos $\mathrm{m}$ uma unidade nos sericos de asa uma unidade hospitalar prisional onde a segurança preva assegura o cumprimento dos aspectos éticos da profissão: respeito à vida, à dignidade e aos direitos da pessoa humana, considerando as especificidades próprias à condição destes clientes.

\section{Referências}

1-Ministério da Saúde (BR). Plano Nacional de Saúde no Sistema Penitenciário. Brasília (DF); 2004.

2-Ornellas CP. Cidadania e direitos sociais. Rev Enferm UERJ 1995; 3(2): 184-88.

3-Lei n 2848, de 07 de dezembro de 1940. Dispõe sobre o Código Penal Brasileiro. São Paulo (SP): Saraiva; 2002.

4-Constituição da República Federativa do Brasil. Brasília (DF): Senado; 1988.

5-Lei $n^{0}$, de 11 de julho de 1984, que institui a Lei de Execução Penal. Dispõe sobre a legislação nacional e os direitos das pessoas sob custódia da justiça. São Paulo((SP): Saraiva, 2004.

6 -Lei $n^{0} 8.080$, de 19 de setembro de 1990. Dispõe sobre as condições para promoção, proteção e recuperação da saúde, a organização e o finuncionaamento dos serviços correspondentes e dá outras providências. Ministério da Saúde (BR); 2000.

7-Lei n. 8.142, de 28 de dezembro de 1990. Dispõe sobre a participação da comunidade na gestão do Sistema Único de Saúde (SUS) e sobre as transferências intergovernamentais de recursos financeiros na área da saúde e dá outras providências. Ministério da Saúde (BR); 2000.

8-Goffman E. Manicômios, prisões e conventos. $7^{\mathrm{a}}$ ed. São Paulo (SP): Perspectiva; 2001.

9-Gil AC. Como elaborar projetos de pesquisa. $4^{\mathrm{a}}$ ed. São Paulo (SP): Atlas; 2002.

10-Polit DF, Hungler BP. Fundamentos de pesquisa em enfermagem. $5^{\mathrm{a}}$ ed. Porto Alegre (RS): Artes Médicas, 2004.

11-Ministério da Saúde (BR). Conselho Nacional de Saúde. Resolução $\mathrm{n}^{\circ} 196$, de 10 de outubro de 1996. Diretrizes e normas regulamentadoras de pesquisas envolvendo seres humanos. Inf Epidemiol SUS 1996; 5 (2 supl 3): 13-41.

12-Figueiredo NMA. Uma perspectiva do cuidar em enfermagem considerando a estética, ecosofia e autopoiese. In: Figueiredo NMA, organizadora. Enfermagem fundamental: realidades, questões e soluções. São Paulo (SP): Atheneu; 2001.

13-Waldow VR. Cuidado humano: o resgate necessário. Porto Alegre (RS): Sagra Luzzatto; 1998.

14-Potter PA, Perry AG. Fundamentos de enfermagem: conceitos, processo e prática. $4^{\mathrm{a}}$ ed. Rio de Janeiro (RJ): Guanabara Koogan; 1999.

15-Backes DS, Sousa FGM, Mello ALSF, Erdmann AL, Nascimento KC, Lessmann JC. Concepções de cuidado: uma análise das teses apresentadas para um programa de pós- graduação em enfermagem. Texto\&Contexto Enferm 2006; 15 (n esp): 71-8.

16-Furegato ARF. Relações interpessoais terapêuticas na enfermagem. Ribeirão Preto (SP): Scala; 1999.

17-Benjamin A. A entrevista de ajuda. $8^{a}$ ed. São Paulo (SP): Martins Fontes; 1994.

Recebido em 14/01/2008 Reapresentado em 14/04/2008 Aprovado em 18/04/2008 